・论坛・ 中国国家公园试点专题

\title{
中国自然保护地整合优化关键问题
}

\author{
高吉喜 ${ }^{*}$, 刘晓曼 ${ }^{1}$, 周大庆 ${ }^{2}$,马克平 ${ }^{03}$, 吴琼 $^{4}$, 李广宇 $^{1}$
}

1. 生态环境部卫星环境应用中心, 北京 100094; 2. 生态环境部南京环境科学研究所, 南京 210042; 3. 中国科学院植物研究所植被与环境 变化国家重点实验室，北京 100093; 4. 世界自然基金会(瑞士)北京代表处，北京 100037

高吉喜, 刘晓曼, 周大庆, 马克平, 吴琼, 李广宇 (2021) 中国自然保护地整合优化关键问题. 生物多样性, 29, 290-294. doi: 10.17520/biods.2021051. Gao JX, Liu XM, Zhou DQ, Ma KP, Wu Q, Li GY (2021) Some opinions on the integration and optimization of natural protected areas in China. Biodiversity Science, 29, 290-294. doi: 10.17520/biods.2021051.

\section{Some opinions on the integration and optimization of natural protected areas in China}

Jixi Gao ${ }^{1 *}$, Xiaoman $\mathrm{Liu}^{1}$, Daqing Zhou ${ }^{2}$, Keping Ma ${ }^{\mathbb{1} 3}$, Qiong $\mathrm{Wu}^{4}$, Guangyu $\mathrm{Li}^{1}$

1 Ministry of Ecology and Environment Center for Satellite Application on Ecology and Environment, Beijing 100094

2 Nanjing Institute of Environmental Sciences, Ministry of Ecology and Environment, Nanjing 210042

3 State Key Laboratory of Vegetation and Environmental Change, Institute of Botany, Chinese Academy of Sciences, Beijing 100093

4 World Wide Fund for Nature (Switzerland) Beijing Representative Office, Beijing 100037

自然保护地建设是国际公认的保护生物多样 性、提供优质生态产品与服务、维系生态系统健康 的最重要和最有效途径。自然保护地作为中国自然 生态空间最精华和最重要的组成部分, 是建设生态 文明的核心载体, 是美丽中国的重要象征, 在维护 国家生态安全中具有首要地位(唐小平等, 2019)。从 1956年建立第一个自然保护地以来, 中国自然保护 地建设取得了巨大成就，保护体系逐步完善，建立 了由自然保护区、风景名胜区、森林公园、地质公 园、湿地公园等组成的数量众多、类型丰富、功能 多样的自然保护地体系。截止到2019年底, 中国已 有各类自然保护地约 1.18 万处, 大约覆盖了陆域国 土面积的 18\%, 占海域面积的 4.6\% (高吉喜等, 2019), 无论从数量上还是面积上均位居世界前列, 为保护生物多样性、自然景观及自然遗迹, 维护国 家和区域生态安全等发挥了重要作用。

然而, 中国自然保护地在建设管理过程中也存 在一些深层次的问题，如在建立程序上通常采取部 门主导、地方自愿、自下而上的申报方式; 管理上 采用地方分割、部门分治的方式。此外还存在各职
能部门之间竞相圈地、权责不清等现象, 以及自然 保护地顶层设计不够、整体性差、协同度低等问题， 影响了其完整性和连通性。因此, 中国自然保护地 总体上尚未形成整体高效、有机联系、互为补充的 自然保护地体系(黄宝荣等, 2018; 唐芳林, 2018), 严重制约了中国自然保护地事业的健康发展, 难以 满足保障国家生态安全、维护生物多样性等要求(唐 小平和橸晓峰, 2017; 唐芳林等, 2019)。

2019年6月，中共中央办公厅、国务院办公厅印 发《关于建立以国家公园为主体的自然保护地体系 的指导意见》, 提出要建立以国家公园为主体、自 然保护区为基础、各类自然公园为补充的自然保护 地体系(http://www.gov.cn/zhengce/2019-06/26/cont ent_5403497.htm), 标志着中国自然保护地体系进 入全面深化改革的新阶段。2020年3月, 自然资源 部、国家林业和草原局印发《关于做好自然保护区 范围及功能分区优化调整前期有关工作的函》, 正 式启动了自然保护地整合优化工作, 表明中国正在 快速推进自然保护地体系重构(https://www.guoturen. com/guihua-347.html)。2020年12月, 全国自然保护 
地整合优化预案评议会在北京召开, 相关部门密切 配合, 在一年内摸清了全国自然保护地本底, 建立 了数据库, 编制了整合优化预案, 解决了一部分历 史遗留问题, 一定程度地优化了自然保护地空间布 局, 为后续整合优化方案的制定及自然保护地体系 的真正落地奠定了坚实基础。

作为生态文明制度改革的具体实现方式和前 沿阵地, 自然保护地整合优化是构建以国家公园为 主体的自然保护地体系的重要举措和关键路径, 是 一项科学性、系统性、复杂性、创新性的工作。如 何科学开展整合优化、切实促进自然保护地可持续 发展是目前自然保护地改革中最紧迫的问题, 关系 着中国新型自然保护地体系建立后的整体效能和 保护成效。为此, 本文针对当前整合优化中存在的 几个关键问题提出了应对思路和举措, 以期为自然 保护地整合优化提供参考。

\section{准确把握自然保护地定位}

自然保护地是由各级政府依法划定或确认, 对 重要的自然生态系统、自然遗迹、自然景观及其所 承载的自然资源、生态功能和文化价值实施长期保 护的陆域或海域(http://www.gov.cn/zhengce/2019-06 /26/content_5403497.htm)。自然保护地包括国家公 园、自然保护区和自然公园三类，其中国家公园的 定位是保护具有国家代表性的自然生态系统; 自然 保护区的定位是保护典型的自然生态系统、珍稀濒 危野生动植物的天然集中分布区、有特殊意义的自 然遗迹区域; 自然公园的定位是保护重要的自然生 态系统、自然遗迹和自然景观，且强调可持续利用。 生态保护红线的定位是承担水源涵养、水土保持、 防风固沙、生物多样性维护、海岸生态稳定等重要 生态功能(http://www.gov.cn/zhengce/2017-02/07/con tent_5166291.htm), 其侧重点在生态功能和生物多 样性优先区保护(中华人民共和国环境保护部, 2011)。国家公园、自然保护区、自然公园和生态保 护红线各有侧重、相互弥补, 形成了中国完整的生 态空间保护体系。

因此, 无论是新建自然保护地，还是整合优化 已有自然保护地, 都只有准确、清晰地把握保护地 的定位才能解决长期以来不同类型自然保护地交 叉重叠、管理目标不明确的问题, 并与其他类型自
然保护体系如重点生态功能区、生态保护红线等相 区别。为此, 在整合优化过程中, 需严格遵照自然 保护地的定位, 明确保护对象, 做到科学、准确地 设立自然保护地。

\section{科学认识现实矛盾冲突}

中国的开发历史悠久，人地交织，自然保护地 内普遍存在人类活动, 如社区居民点、耕地、能源 开发、矿产开采、旅游活动、道路建设等。2015年 的遥感监测发现, 中国国家级自然保护区内人类活 动的分布非常普遍, 总面积约 2.85 万 $\mathrm{km}^{2}$, 总数量 156,061处(刘晓曼等, 2020)。造成人类活动频繁的原 因是多方面的，其中最重要的两个是：(1)我国人多 地少，除了高原和荒漠等不适宜人类居住的地区之 外，其他区域人口众多，分布广泛; (2)我国自然保 护地建设和管理过程中存在很多体制机制等深层 次的原因, 在划定保护区时未科学规划保护范围, 管理不到位导致社会经济活动不断侵入保护地。

同时我们需要认识到, 自然保护地内存在人类 活动并不代表就是对自然保护地的破坏，有些人类 活动反而是有利于自然保护地发展的。自然保护地 内的人类活动大致可分成三类: 第一类是有明显负 面影响的活动，如大面积的城镇建设区、矿产资源 开发等; 第二类是与管理密切相关的人类活动, 如 放牧、林下产业等，如果管理得好，有利于生态保 护，如管理得不好，则会破坏生态; 第三类是有利 于自然保护地保护的人类活动, 主要是部分野生动 物如朱噮(Nipponia nippon)、黑颈鹤(Grus nigricollis) 等, 需要与人类活动共存共生。

所以，人类活动并不等同于人类干扰，只有那 些对主要保护对象带来干扰和威胁、对生态环境造 成一定破坏的人类活动才能称之为人类干扰，才会 造成人地矛盾冲突。自然保护地整合优化是为了更 好地进行生态保护, 建立人与自然和谐共生的新模 式。因此, 在此次整合优化中，既要秉持严格保护 的原则, 也要以开放的视野、包容的思维、先进的 理念和分门别类的思路认识和处理人类活动, 科学 甄别哪些是对自然保护地干扰较大的人类活动, 哪 些是能与自然和谐共生的人类活动, 并根据不同保 护对象、不同保护地类型和不同功能区分别制定调 整规则, 以维护自然保护地的完整性。 


\section{3 少开“天窗”，保持生态系统完整性}

保护生态系统完整性和原真性是构建以国家 公园为主体的自然保护地体系的基本目标, 这个完 整性主要是指地域上的连续性、价值上的整体性、 功能上的完整性、人与自然的和谐性(李金路等, 2020)。自然保护地在地域空间上应该是完整的、连 续的地域实体, 而不是分散的若干斑块; 生态系统 的完整性既包括自然生态系统和生态过程的完整 性, 也包括人文生态系统的完整性。因此, 在自然 保护地整合优化过程中, 不能为了减少矛盾冲突、 规避监管压力而广开“天窗”, 这会人为造成自然保 护地在空间上的破碎化, 进而影响保护成效, 实际 上是避监管、免追责的不负责任的态度。因此, 整 合优化中要全程贯彻整体保护的思维, 牢固树立 “山水林田湖草是一个生命共同体”的理念、严格遵 循生态系统及重要栖息地完整性的保护原则, 按照 资源价值连续性的要求来开展。

生态保护与人类活动的关系是此次整合优化 无法回避的问题。整合优化的目的是更有效地保护 和管理好自然保护地并发挥其作用，不能仅仅为了 管理的便利就把人类活动一股脑划出去, 而要从根 本上解决人地矛盾冲突。我国是一个拥有五千多年 开发历史的古国, 如果过分追求单纯的原始区域, 现实中很难做到。事实上, 纵观各国自然保护地的 发展历程, 其重要特征就是人与自然的和谐共生, 生态效益和社会效益的协同发展。自然保护地是涉 及自然与人、社会、经济多方交织的复合体, 一味 地开 “天窗”不是上策。对于占地面积大、空间上连 片、生态影响突出, 以及位于边界的人类活动, 在 不影响主体功能的情况下应该调出, 而对于自然保 护地内部零散分布的耕地、商品林、村民建设用地 等, 则要从系统思维、整体视角出发, 以优化规则、 强化管理的方式允许其存在。一方面, 引导其规范 活动范围和强度, 做好防控, 最大限度减少对主要 保护对象的干扰和破坏; 另一方面, 要加大生态补 偿力度, 促进社会公平, 实现生态保护与经济利益 的统一。

总之, 要做好科学评估后再酌情调整自然保护 地人类活动, 确定开 “天窗” 的范围和大小, 不能简 单地一刀切, 否则会造成自然保护地在空间上的破 碎化, 甚至因为调出后无法被监管导致对自然保护
地的损害。事实上，开“天窗”表面上甩掉了包袱，实 际上并不能从根本上解决存在的矛盾。所以, 正确 的做法应是在保证自然保护地完整性的前提下, 科 学论证调出的合理性, 将重点由 “如何调” 转向 “如 何管”, 通过优化管控规则, 利用先进的管理理念 和有效的监管方式, 来减少人类活动对自然资源和 保护对象的破坏，实现人与自然的永久和谐。

\section{妥善处理历史遗留问题}

我国早期采取抢救式保护的策略, 新建了一大 批自然保护地, 对保护中国自然资源和生物多样性 发挥了重要作用。但早期很多自然保护地的边界划 定技术水平有限, 加上经济社会不断发展, 导致很 多村庄甚至城镇建成区被划入自然保护地, 带来大 量的历史遗留问题。根据《关于做好自然保护区范 围及功能分区优化调整前期有关工作的函》，仅国 家级自然保护区内就有城市建成区29个, 建制乡镇 建成区531个, 人口约400万, 耕地 146 万ha (https:// www. guoturen.com/guihua-347.html)。大量的人类活 动成为此次自然保护地调整中最普遍、最难解决的 难题。

如前所述, 自然保护地不是封闭、隔离的孤岛, 其与长期生活在此的老百姓的生产生活息息相关、 密不可分, 但是现有部分人类活动与自然保护地的 理念相违背。为此, 应统筹保护与居民生活生产发 展的关系, 科学客观地解决好历史遗留问题。一方 面, 要注重自然保护地的生态完整性, 最大程度地 保护好保护地内的自然资源和物种资源; 另一方面, 全民公益性是自然保护地的理念之一, 要兼顾保护 地内居民的利益, 保证人民群众利益的最大化。基 于此, 建议在自然保护地整合优化过程中以更宏观 和更长远的视野, 针对不同类型的历史遗留问题分 类进行处置: (1)自然保护地内尤其是核心区的村镇 要有条件地逐步退出。(2)确定无法退出的, 可以设 立过渡期, 同时要加强对其生产生活的监管, 完善 相关规章制度并加强宣传, 促进社区居民知法、懂 法、守法。(3)建立健全生态补偿制度, 对无需搬出 又因保护生态环境而影响发展的社区居民, 给予一 定的经济补偿。(4)建立共建共管机制, 将部分社区 居民转化为护林员、协管员等, 激发社区居民的主 人翁意识, 自觉参与到保护中, 增强归属感和保护 自觉性, 成为自然保护地的守护者。 


\section{分步做好顶层设计和整体规划}

当前, 我国自然保护地存在交叉重叠、多头管 理、空间布局不完善、海洋类型自然保护地保护空 缺明显等问题, 重要原因之一在于中国的自然保护 地建设没有经过系统的整体规划。目前, 中国正在 开展以国家公园为主体的自然保护地体系建设改 革，是我国自然保护领域前所未有的契机。但当下， 自然保护地整合优化任务重、时间紧，难以同时开 展自然保护地顶层设计。为此, 建议在整合优化工 作结束后，尽快启动国家层面的自然保护地顶层设 计: (1)遵循习近平生态文明思想, 加强自然保护地 顶层设计的内涵研究。(2)开展自然保护地顶层设计 的方法学和实现路径研究, 包括保护地面积和边界 设定的技术方法, 建立起系统的设计技术方案。(3) 统筹研究不同自然保护地的空间布局, 合理规划各 级各类自然保护地的数量与规模, 从而使保护地从 个别、分散的生态系统保护向集中、整体的生态系 统群保护转变(唐芳林等, 2018), 更好地发挥自然保 护地在维护国家生态安全中的作用。

虽然开展顶层设计是当务之急, 但这不是在短 期内能够完成的, 需要动员方方面面的力量。因此, 在本次整合优化中, 不能要求一步到位, 而应分步 实施。建议在本次整合优化中, 重点解决自然保护 地交叉重叠、主要矛盾冲突等问题。然后, 利用3-5 年时间，采取自上而下和自下而上相结合的方式， 全面开展顶层设计, 明确保护空缺, 通过逐步新建 扩建自然保护地、构建生态廊道等措施完善自然保 护地体系。

\section{6 展望与结语}

自然保护地整合优化是构建以国家公园为主 体的自然保护地体系的重要组成部分，对中国自然 保护地体制改革至关重要。如何整合优化是一项政 策与技术紧密结合的复杂工作，在具体实践过程中 会碰到各式各样的矛盾冲突和问题, 需要既面对现 实又继承发展，既开拓创新又慎重前行。在整合优 化过程中, 需不断探索科学之策, 为建立分类科 学、布局合理、保护有力、管理有效的自然保护地 体系筑牢基石，为美丽中国建设奠定根基。

目前, 我国自然保护地整合优化已经取得了重 要阶段性成果。今后, 建议进一步做好以下三方面
工作:

(1)做好科学调查和评估。基于科学评估, 进一 步完善预案, 切实提高预案质量, 使整合优化工作 经得起历史检验，对得起党中央、国务院的嘱托。

(2)开展顶层设计。深入研究顶层设计规则，全 面开展中国自然保护地顶层设计，编制国家层面的 自然保护地发展规划，为建立系统的自然保护地体 系奠定基础。

(3)坚持立法先行。做好《自然保护地法》《国 家公园法》的制定和《中华人民共和国自然保护区 条例》《风景名胜区条例》的修订工作，将加强生态 环境监管、落实“保护面积不减少、保护强度不降 低、保护性质不改变”、细化管控要求等纳入相关 立法，切实为整合优化提供坚实的法律保障。

\section{ORCID}

马克平 (D) https://orcid.org/0000-0001-9112-5340

\section{参考文献}

Gao JX, Xu MJ, Zou CX (2019) Development achievement of natural conservation in 70 years of new China. Chinese Journal of Environmental Management, 11(4), 25-29. (in Chinese with English abstract) [高吉喜, 徐梦佳, 邹长新 (2019) 中国自然保护地70年发展历程与成效. 中国环境 管理, 11(4), 25-29.]

Huang BR, Ma YH, Huang K, Su LY, Zhang CL, Cheng DW, Wang Y (2018) Strategic approach on promoting reform of China's natural protected areas system with national parks as backbone. Bulletin of Chinese Academy of Sciences, 33, 1342-1351. (in Chinese with English abstract) [黄宝荣，马 永欢, 黄凯, 苏利阳, 张丛林, 程多威, 王毅 (2018) 推 动以国家公园为主体的自然保护地体系改革的思考. 中 国科学院院刊, 33, 1342-1351.]

Li JL, Chen YH, Wu CZ, Zhang TS, Liu Y, Shi LX, Tang XL, Sun YT (2020) Natural reserve system: Chinese approach. City Planning Review, 44(2), 50-58. (in Chinese) [李金路, 陈耀华，吴承照，张同升，刘英，史丽秀，唐晓岗，孙铁 烦 (2020) 自然保护地体系: 中国方案. 城市规划, 44(2), 50-58.]

Liu XM, Fu Z, Wen RH, Jin CP, Wang XF, Wang C, Xiao RL, Hou $P$ (2020) Characteristics of human activities and the spatio-temporal changes of national nature reserves in China. Geographical Research, 39, 2391-2402. (in Chinese with English abstract) [刘晓曼，付卓，闻瑞红，靳川平，王 雪峰, 王超, 肖如林, 侯鹏 (2020) 中国国家级自然保护 区人类活动及变化特征. 地理研究, 39, 2391-2402.]

Ministry of Environmental Protection of the People's Republic of China (2011) China Biological Diversity Protection Action Plan (2011-2030). China Environmental Science 
Press, Beijing. (in Chinese) [中华人民共和国环境保护部 (2011)中国生物多样性保护战略与行动计划(2011-2030 年). 中国环境科学出版社, 北京.]

Tang FL (2018) Protection and management of nature park under the national park system. Forestry Construction, (4), 1-6. (in Chinese with English abstract) [唐芳林 (2018) 国 家公园体制下的自然公园保护管理. 林业建设, (4), 1-6.]

Tang FL, Wang MJ, Sun HY (2018) Analysis on establishing the protected area system dominated by national park. Forestry Construction, (1), 1-5. (in Chinese with English abstract) [唐芳林, 王梦君, 孙鸿雁 (2018) 建立以国家公 园为主体的自然保护地体系的探讨. 林业建设, (1), 1-5.]

Tang FL, Wang MJ, Sun HY (2019) Reform path on management system of natural protected area. Forestry Construction, (2), 1-5. (in Chinese with English abstract)
[唐芳林, 王梦君, 孙鸿雁 (2019) 自然保护地管理体制 的改革路径. 林业建设, (2), 1-5.]

Tang XP, Jiang YF, Liu ZL, Chen JZ, Liang BK, Lin C (2019) Top-level design of the natural protected area system in China. Forest Resources Management, (3), 1-7. (in Chinese with English abstract) [唐小平, 蒋亚芳, 刘增力, 陈君帜, 梁兵宽, 萄琛 (2019)中国自然保护地体系的顶层设计. 林业资源管理, (3), 1-7.]

Tang XP, Luan XF (2017) Developing a nature protected area system composed mainly of national parks. Forest Resources Management, (6), 1-8. (in Chinese with English abstract) [唐小平, 奕晓峰 (2017) 构建以国家公园为主 体的自然保护地体系. 林业资源管理, (6), 1-8.]

(责任编委: 徐卫华 责任编辑: 周玉荣) 